\title{
PROSPECTIVE TEACHERS UNDERSTANDING FRACTION DIVISION USING RECTANGLE REPRESENTATION
}

\author{
Muhammad Ghiyats Ristiana ${ }^{* 1,2}$, Dadang Juandi ${ }^{1}$, Sulistiawati ${ }^{3}$ \\ ${ }^{1}$ Universitas Pendidikan Indonesia, Indonesia \\ ${ }^{2}$ Institut Keguruan dan Ilmu Pendidikan Siliwangi, Indonesia \\ ${ }^{3}$ Sekolah Tinggi Keguruan dan Ilmu Pendidikan Surya, Indonesia
}

\begin{tabular}{l}
\hline \hline Article Info \\
\hline Article history: \\
Received Jan 1, 2021 \\
Revised Jan 15, 2021 \\
Accepted Jan 16, 2021 \\
\hline
\end{tabular}

\section{Keywords:}

Fraction Division, Keep-Change-Flip Algorithm, Prospective Teachers, Rectangle Representation

\begin{abstract}
Fraction division is one of the most difficult subjects in elementary school. Not only elementary students but many prospective teachers don't understand the fraction division concept yet-most of them using a keep-change-flip algorithm to solve fraction division problems. A study using rectangle representation was conducted by us to prospective teachers. This study aims to see whether this rectangle representation will make prospective teachers understand or not. To do so, we made a mixed-method study with 80 prospective teachers as participants. The results show that $53,75 \%$ of prospective teachers use the keep-change-flip algorithm without understanding the concept of fraction division, and just $15 \%$ of prospective teachers understand fraction division. We assume that most prospective teachers still can't imagine how fraction division works in a real-life context. They remember what they used to do to finish the fraction division problem that their teacher has introduced in primary school. Based on the results, we conclude that the study with rectangle representation still needs an improvement, whether the teacher's explanation or the rectangle media.
\end{abstract}

Copyright $(2021$ IKIP Siliwangi. All rights reserved.

\section{Corresponding Author:}

Muhammad Ghiyats Ristiana,

Department of Mathematics Education,

Universitas Pendidikan Indonesia,

Jl. Dr. Setiabudhi No. 229, Bandung, West Java 40154, Indonesia.

Email: mgristiana@upi.edu

\section{How to Cite:}

Ristiana, M. G., Juandi, D., \& Sulistiawati, S. (2021). Prospective teachers understanding fraction division using rectangle representation. Infinity, 10(2), 161-174.

\section{INTRODUCTION}

Fraction division is one of important subjects to learn, this concept can be utilized by students to solve their problems. For instance, when we want to divide $1 / 2$ piece of cake to 3 people, and many more. As we know, formally fraction division problem usually solved by keep-change-flip algorithm. This was an easy problem to solve, but its difficult to understand how this algorithm can solve the fraction division problems. Common Core State Standards Initiative (CCSSI) states that fraction subject began to be taught from third grade in elementary school (Bentley \& Bossé, 2018). 
However, fraction operation subjects still quite difficult in elementary school students, especially fraction division (Fitri \& Prahmana, 2019; Purnomo et al., 2019; Widada et al., 2020; Yeo, 2019). They still assuming that if a number divided by another, it will be smaller than before (Ervin, 2017; Yeo, 2019). Besides that, they still using keep-change-flip algorithm to solve the fraction problems without understanding the meaning of fraction division and how that algorithm valid mathematically (Alenazi, 2016; Bentley \& Bossé, 2018; Purnomo et al., 2019; Sahin et al., 2020; Whitehead \& Walkowiak, 2017; Yeo, 2019).

Many things that can affect this problem, one of them is teacher habits that tends to give keep-change-flip algorithm directly to be memorized, remembered and implemented without telling them the concept of fraction division and how that algorithm valid mathematically (Apsari et al., 2020; Bentley \& Bossé, 2018; Haji, 2013; Purnomo et al., 2019; Whitehead \& Walkowiak, 2017). Fraction division also have the different meaning, so students still not properly understand the meaning of fraction division. Fraction division known as measurement concept usually done with repeated substraction until the number that are divided become zero (Purnomo et al., 2019; Stohlmann et al., 2020; Widada et al., 2020). Furthermore, fraction division also known as equal share, for instance there is a half of cake that will be divided into a quarter of cake, how many person that will get that cake (Purnomo et al., 2019; Stohlmann et al., 2020).

There are many ways to understand about the fraction division problems, and maybe if we are a creative person, it can be a new method to understand the fraction division problems. There are some ways to understand fraction division problems (Adu-Gyamfi et al., 2019) (see Table 1).

Table 1. Fraction division problems concept

\begin{tabular}{|c|c|c|}
\hline Concept & Example in verbal representation & Algorithm \\
\hline $\begin{array}{l}\text { Measurement } \\
\text { Division }\end{array}$ & $\begin{array}{l}\text { Needed } \frac{c}{d} m^{2} \text { fabric to make one cloth. } \\
\text { How many clothes that can make if just } \\
\text { have } \frac{a}{b} m^{2} \text { fabric? }\end{array}$ & $\frac{a}{b} \div \frac{c}{d}=\frac{a d}{b d} \div \frac{b c}{b d}=a d \div b c$ \\
\hline \multirow[t]{2}{*}{$\begin{array}{l}\text { Partitive } \\
\text { Division }\end{array}$} & $\begin{array}{l}\text { Aldo has } \frac{a}{d} \text { chocolate that will be share } \\
\text { with } c \text { friends. How many chocolates for } \\
\text { each friend? }\end{array}$ & $\frac{a}{b} \div c=\frac{a \div c}{b}$ \\
\hline & $\begin{array}{l}c \text { people bought } \frac{a}{b} \mathrm{~kg} \text { chocolates that will } \\
\text { be shared equal. How many chocolates for } \\
\text { each person? }\end{array}$ & $\frac{a}{b} \div c=\frac{a}{b \times c}$ \\
\hline $\begin{array}{l}\text { Determination } \\
\text { of unit rate }\end{array}$ & $\begin{array}{l}\text { Lanaya use } \frac{a}{b} \text { part of corned beef to make } \\
\frac{c}{d} \text { servings of fried rice. How many } \\
\text { servings that she can make if she uses a } \\
\text { whole of corned beef? }\end{array}$ & $\frac{\frac{a}{b}}{\frac{c}{d}}=\frac{\frac{a}{b} \times \frac{d}{c}}{\frac{c}{d} \times \frac{d}{c}}=\frac{a d}{b c}$ \\
\hline $\begin{array}{l}\text { Inverse of } \\
\text { multiplication }\end{array}$ & $\begin{array}{l}\text { From survey conducted to } a \text { students, } \frac{c}{d} \\
\text { students like mathematics subject and the } \\
\text { others like biology subject. How many } \\
\text { parts of students that like biology subject? }\end{array}$ & $a \div \frac{c}{d}=\frac{d}{c} \times a$ \\
\hline
\end{tabular}

To introduce the fraction concept, especially for fraction division, a study was present by Klemer, Rapoport, and Lev-Zamir (2019) that see how teacher tell students about fraction concept, especially fraction division concept. There are 3 ways to teach conducted by the 
participant of Klemer et al. (2019) state that First, they illustrate fraction fivision with picture as grouping. Checking how many divisors that are in the divider or checking how many second fraction that are in first fraction; Second, gradually explanation. They tend to explain a real problem about fraction, make an equation where divisor as a whole, division operation integer with fraction, fraction with integer, fraction with fraction with same denominator, and fraction with fraction with different denominator; Third, presenting students' assumptions till using keep-change-flip algorithm. They will give a problem verbally about fraction division which make it possible to students to solve the problems in a various way.

\section{The Experiential Learning Cycle}

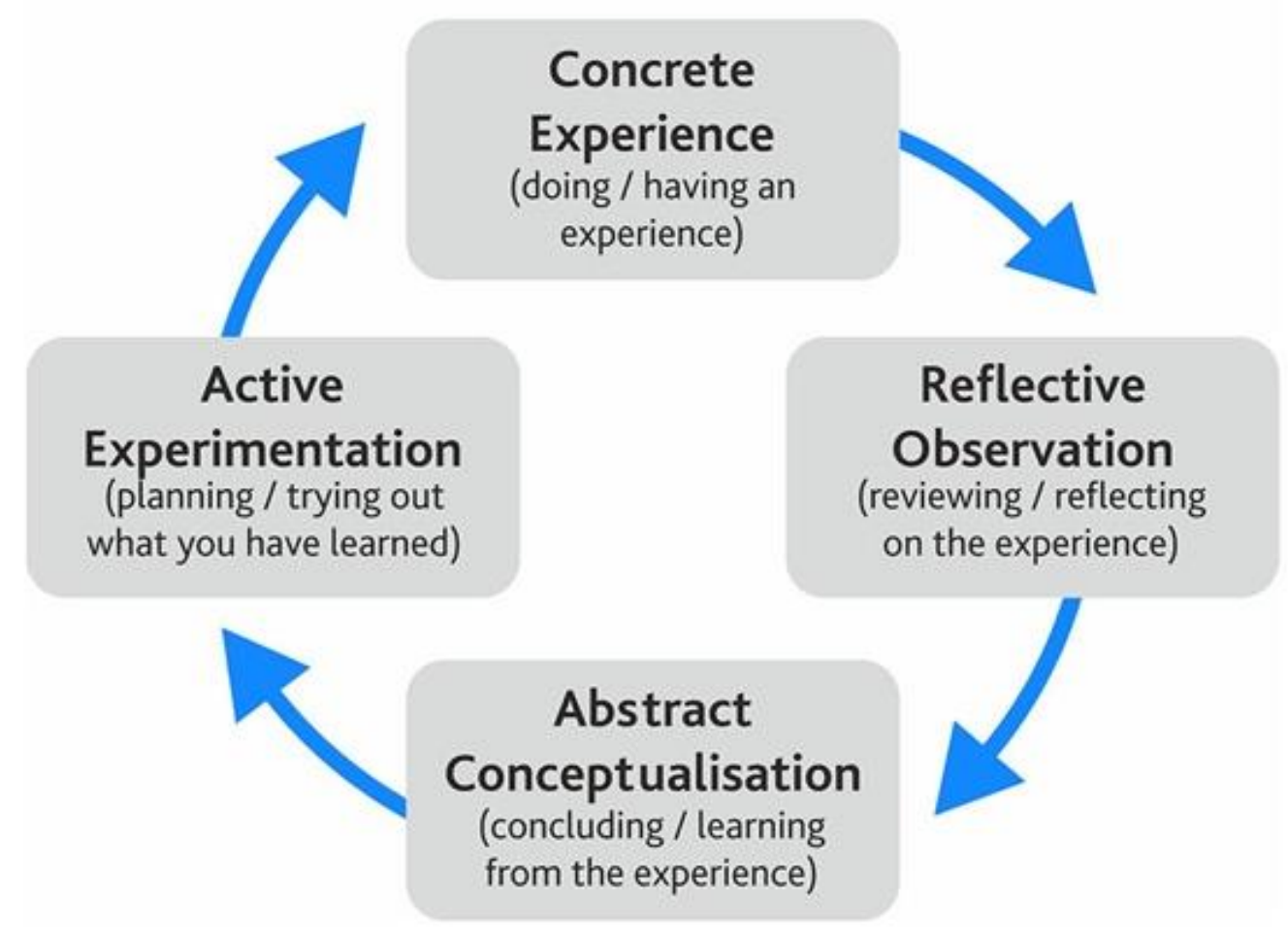

Figure 1. The Kob's experiential learning cycle

To make students understand about the fraction division, some media needed to be conducted to support their knowledge about this. A teacher should think how to make students understand about what have been learned. Therefore, we try to make a rectangle representation media that may can make students easier to understand fraction division. This is based on Kob's experiential learning cycle that we can conducted a lesson from concrete experience until active experimentation (Konak et al., 2014) (see Figure 1).

Concrete experience that students should feel by themselves what they've learned during the lesson. Concrete thing should be conducted especially in elementary school students. They tend to understand with the concrete media rather than the abstract one. So, students will be understood what the teacher said. Then reflective observation where students doing some activity such as discussion with their friends, asking each other questions to reflective their experience. Asking a question not always to be focused on the teacher, they can ask their friends to have their friend's opinion about their understanding. The third cycle is abstract conceptualization where students can make a theoretical models and generalization from what they've learned. This model which is called abstraction from a 
concept. Mathematics will become abstract later, they can't deny it. The last cycle is active experimentation, where they are planning and trying out what they've learned. There are two strategies, giving students a new task or combine some topics that connected with same activities. It is intended to see whether students are ready to have the next material or not, and whether the students are already understanding about the material that has been taught.

We refer to the concrete experience first for making the students understand until they can active experimentation with the fraction division. As a teacher, we should be aware of the students answer about fraction division. So, a teacher must understand about the fraction division concept for reducing misconception about that topic (Stohlmann et al., 2020). A teacher should introduce representation form that can be usefull for students, ask students to draw some fraction concept and proof that, and teacher should design how they do an assessment for students to see their understanding about fraction division.

Before teaching some materials, teachers should have a very good understanding about that concepts. So it is with fraction materials, especially fraction division which is known as a very difficult concept to understand among the elementary school students (Purnomo et al., 2019; Widada et al., 2020; Yeo, 2019). Therefore, teachers should know many different representations about fraction division to teach well about that. However, many prospective teachers even teachers still not understand about this fraction division concept (Alenazi, 2016; Whitehead \& Walkowiak, 2017). They still use keep-change-flip algorithm but not understanding about the fraction division concept (Sahin et al., 2020). Based on our preliminary studies, in one of university in Cimahi, Indonesia prospective teachers still not understand about fraction division. So, we decide to make an algorithm that may help prospective teachers understand about the fraction division. The aim of this study is to see whether prospective teachers understand about fraction division after they learn with this rectangle representation or not.

Fraction division can be represented by water filling from the big bottle to smaller one. Suppose $1500 \mathrm{ml}$ bottle considered as a whole, then $500 \mathrm{ml}$ bottle considered as $\frac{1}{3}$ part, $250 \mathrm{ml}$ bottle considered as $\frac{1}{6}$ part, etc. There is one $1500 \mathrm{ml}$ bottle and one $500 \mathrm{ml}$ bottle that filled with water. All of the water will be poured to $300 \mathrm{ml}$ water. How many $300 \mathrm{ml}$ bottle that needed?

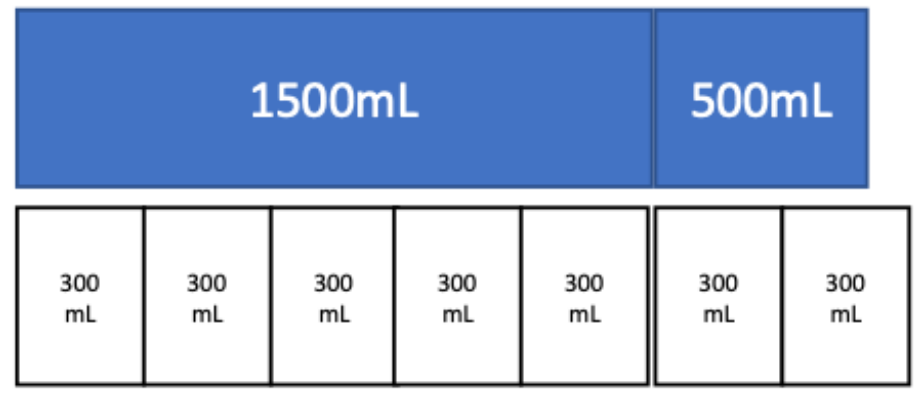

Figure 2. Rectangle which represents the size of each bottle

We know that $1500 \mathrm{ml}$ bottle as a whole, $500 \mathrm{ml}$ bottle as $\frac{1}{3}$ part, and $300 \mathrm{ml}$ bottle as $\frac{1}{5}$ part. So, we have $1 \frac{1}{3}$ water that will be poured into $\frac{1}{5}$ part bottle. Mathematically, we can write $1 \frac{1}{3} \div \frac{1}{5}$ and we can use keep-change-flip algorithm to solve that problem.

$$
1 \frac{1}{3} \div \frac{1}{5}=\frac{4}{3} \div \frac{1}{5}=\frac{4}{3} \times \frac{5}{1}=\frac{20}{3}=6 \frac{2}{3}
$$


As we know that there are still many students think the result of division will be smaller than a number that will be divided.

However, in this case the result is bigger than a number that will be divided and they may confused why the result is bigger (Ervin, 2017; Yeo, 2019). From this we try to make a rectangle which represent the size of each bottle (see Figure 2).

The answer of that problem is $6 \frac{2}{3}$, the six $300 \mathrm{ml}$ bottle can be seen on that rectangle representation, but how can we have $\frac{2}{3}$ ? As we know that we have $2000 \mathrm{ml}$ water that will be poured into $300 \mathrm{ml}$ bottle. So, we have to prepare seven $300 \mathrm{ml}$ bottles to accommodate all of the water, because it will be $2100 \mathrm{ml}$. All of water can be poured into seven $300 \mathrm{ml}$ bottles, but the last $300 \mathrm{ml}$ bottle will not full and leaving $100 \mathrm{ml}$. From this case we can know that $100 \mathrm{ml}$ from $300 \mathrm{ml}$ is $\frac{1}{3}$ part. So, we know that the last $300 \mathrm{ml}$ bottle is $\frac{2}{3}$ fulfill with water.

Given this rectangular representation will be easier to count, it's just the last bottle will need more effort to count. Rectangle representation with a number will be easier to count, however if we know only the fraction maybe it will be difficult to solve. From that problem we try to make a rectangle representation steps. Figure 3 represents the problem above but without number.

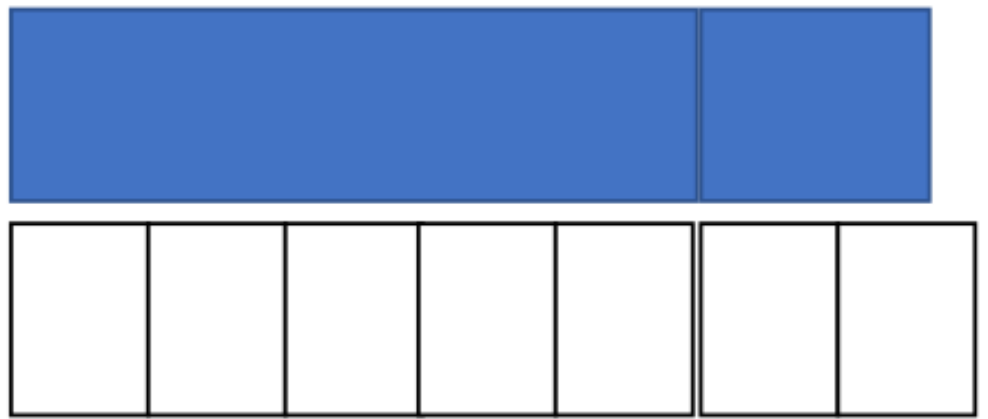

Figure 3. Rectangle which represents the problem

Figure 4 shows that there are seven $\frac{1}{5}$ part will be poured with the $\frac{4}{3}$ water. We know that there will be an empty space in the last $\frac{1}{5}$ part that should we know to complete solving that problem. We can take the difference between white and blue rectangle, we called that the missing piece.

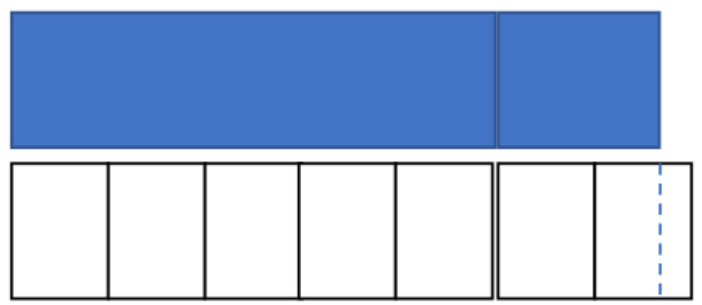

Figure 4. The missing piece

Shortly, we can write the algorithm of this rectangle representation step by step are as follows:

a. Known $A$ and $B$ as a fraction and we have a problem $A \div B$. 
b. First, we have to know whether $A<B$ or $A>B$.

c. Draw a rectangle that represents of each fraction.

d. Duplicate the smaller rectangle until the size is equal or more to the bigger rectangle.

e. Look for the difference between the smaller rectangle and bigger rectangle, we can call that the missing piece.

f. Do the repeated substraction of all the smaller rectangle that have been duplicated with the missing piece, now we know how many parts of missing piece that fulfilled all of the smaller rectangle.

g. Now put the bigger rectangle into all of the smaller rectangle and count it as a fraction with a whole as the smaller fraction.

We try to apply that rectangle representation into a fraction division learning on prospective teachers. The aim of this study is to see whether this representation can make prospective teachers understand about the fraction division or not.

\section{METHOD}

The method used in this study is mixed method, quantitative with random sampling then qualitative descriptive method with case study design. Eighty prospective teachers participated in this study to see their understanding about fraction division. The answer of that students will be categorized into 4 answer (Apsari et al., 2020), are as follows: (a) No answer; (b) Keep-change-flip; (c) Not complete explanation; and (d) Mathematically and example explanation.

We used test and interview as the instrument of this study. Before we conducted the instrument, we apply the rectangle representation to a fraction division lesson. After that, we conducted the test to all of participant that have been attend on that lesson. The test use to know how far hey understand about fraction division, and the interview is to know deeper about their answer and their understanding in fraction division. The instrument of the test are as follows (see Figure 5):

1. Why the division should change to multiplication and the second fraction should change to its invers?

2. The result of $\frac{2}{3} \div \frac{3}{4}$ is ...

3. How you explain this fraction division concept to students?

Figure 5. The instruments test

First question is to see how prospective teachers using their knowledge to solve fraction division, second question is to see whether prospective teachers know why keepchange-flip algorithm valid mathematically, and last question is to see how they will tell students about fraction division concept so the students will not wrong again about the meaning of fraction division operation.

The interview conducted after we analyzed their answers, and we just take one person for each category to know why they answer like that. We interviewed them with unstructured interview design. We are chasing their answer until we get what we want. After we interviewed them, we try to combine the answer between test and interview results. 


\section{RESULTS AND DISCUSSION}

\subsection{Results}

After a lesson using rectangle representation was done, we conducted a test using the instrument above to all eighty participants. After finishing the test, we analyzed the answer of the prospective teachers and make it into 4 categorized. The following Table 2 is the percentage of answers from 80 prospective teachers with 4 categorized:

Table 2. Percentage of answers from prospective teachers into 4 categorized

\begin{tabular}{lcc}
\hline \multicolumn{1}{c}{ Category } & $\begin{array}{c}\text { The number of } \\
\text { prospective teachers }\end{array}$ & Percentage \\
\hline No answer & 3 & $3.75 \%$ \\
Keep-change-flip & 43 & $53.75 \%$ \\
Not complete explanation & 22 & $27.50 \%$ \\
Mathematically and example explanation & 12 & $15.00 \%$ \\
\hline
\end{tabular}

Table 2 shows that $3.75 \%$ prospective teachers have no answer, they can't answer correctly, whether they don't understand the problem or even they don't know how to solve it. Also, we know that $53.75 \%$ prospective teachers prefer using keep-change-flip algorithm to solve the problem, but they still can't understand about the fraction division. It can be seen from their answers that they just use the algorithm without giving the proper explanation about the fraction division. $27.50 \%$ prospective teachers answered correctly and give the explanation, but the explanation is not complete, so we can't understand the whole of their answer. $15.00 \%$ prospective teachers answered correctly and can give a proper explanation with example and mathematically explanation.

After we categorized their answer, then we take one from each category that will be interview. We want to know more about their answers, and why they answer like that. The interviewed is unstructured interview, we just refer to their test answer to know deeper about their answer.

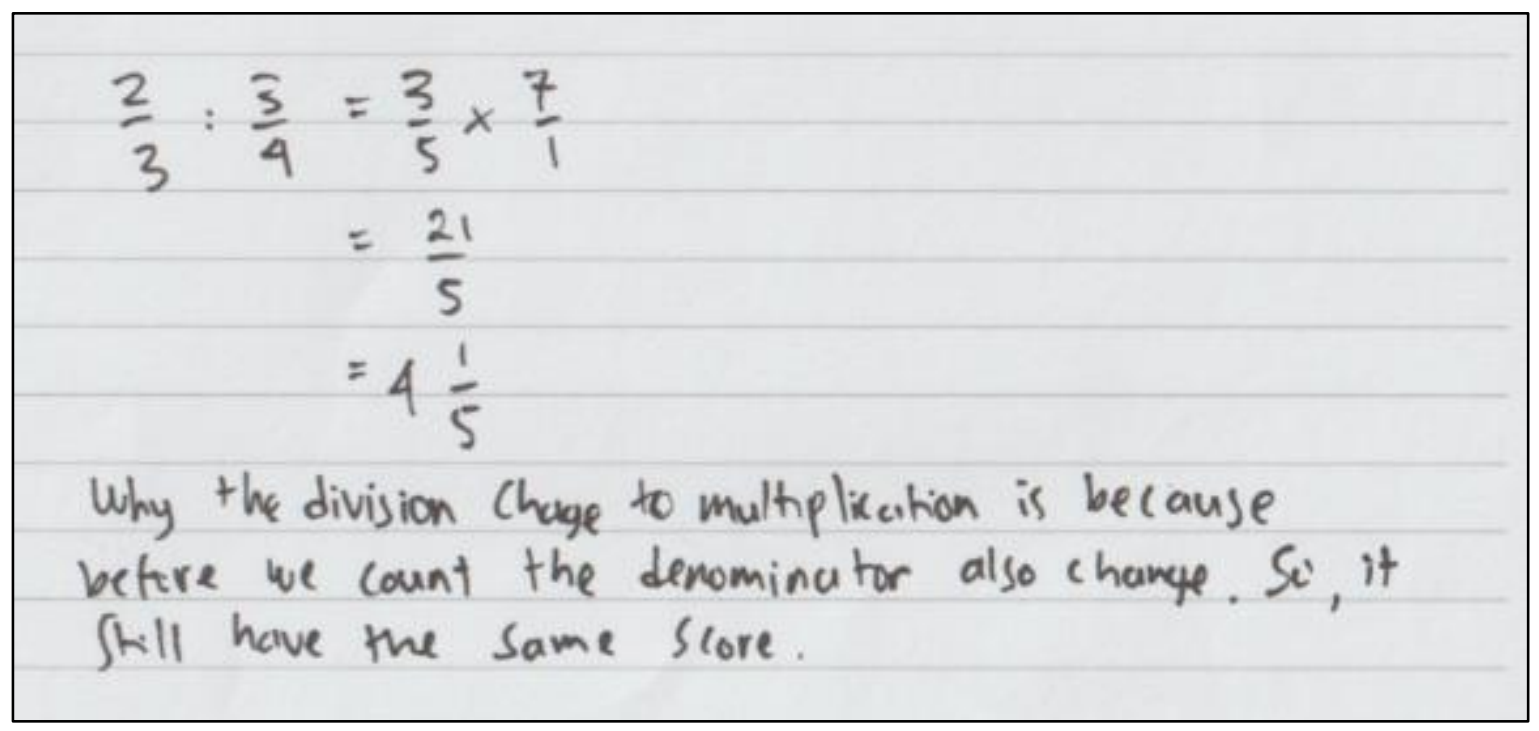

Figure 6. The prospective teacher answer that represents "No Answer" category 
Figure 6 show that the prospective teacher answer is wrong. He used keep-changeflip algorithm, but not have done correctly so the answer is not correct. Three of the No Answer category almost answer same as this. Based on Figure 6, prospective teachers who answer that said that "why the operation become multiplication because before it counts, the denominator also switched so the fraction still have an equal number. We don't know why they didn't know the concept of fraction division. Whether the lesson is not suitable with him or indeed he can't understand about the fraction division. Therefore, we try to interview him to know deeper about his answer and to see whether he understand about fraction division or not.

After we interviewed him, we know that he experienced the misconception about fraction division. He explains that the denominator is added by the numerator so the operation will be $\frac{1}{5} \div \frac{1}{7}$ and because 3 is in both fractions so the first fraction is multiplied by 3 so the operation will be $\frac{3}{5} \div \frac{1}{7}$. He knows that fraction division can be done using keepchange-flip algorithm, so the operation will be $\frac{3}{5} \times \frac{7}{1}$ and the answer as in the picture above. We don't understand why he answer like this because this thing is not accordance with fraction division concept. We conclude that he still not understands about fraction division and how to solve it even with keep-change-flip algorithm. After that interviewed, we try to explain his mistake and give the proper answer. So, he will not wrong again if he wants to solve fraction division problems later.

Also, we ask about how he will teach students about fraction division. He answers that he will give the students keep-change-flip algorithm after being told by us about the correct solution for fraction division problems. And he won't tell any more, just tell the students about keep-change-flip algorithm. We conclude that one of the prospective teachers can't teach fraction division properly. He needs to improve their knowledge about fraction division problems. So, he will be ready to teach this topic and make students understand properly about fraction division.

Most of prospective teachers in this study answer using keep-change-flip algorithm without giving their reasons why they answer using that algorithm. There are some of prospective teachers that give their reasons about why they answer using keep-change-flip algorithm. However, as we can see in Figure 7 that the reasons are not explain why keepchange-flip algorithm can be used and valid mathematically, but they explain that using this algorithm is easier than solve the problem directly. We're interested on their reason that tell us about easier using keep-change-flip algorithm than solve the problem directly, what solve the problem directly mean. So, we decided to interview one of them to know deeper about their reasons of their answer and to see whether they understand about fraction division properly or they still don't understand about fraction division properly. 


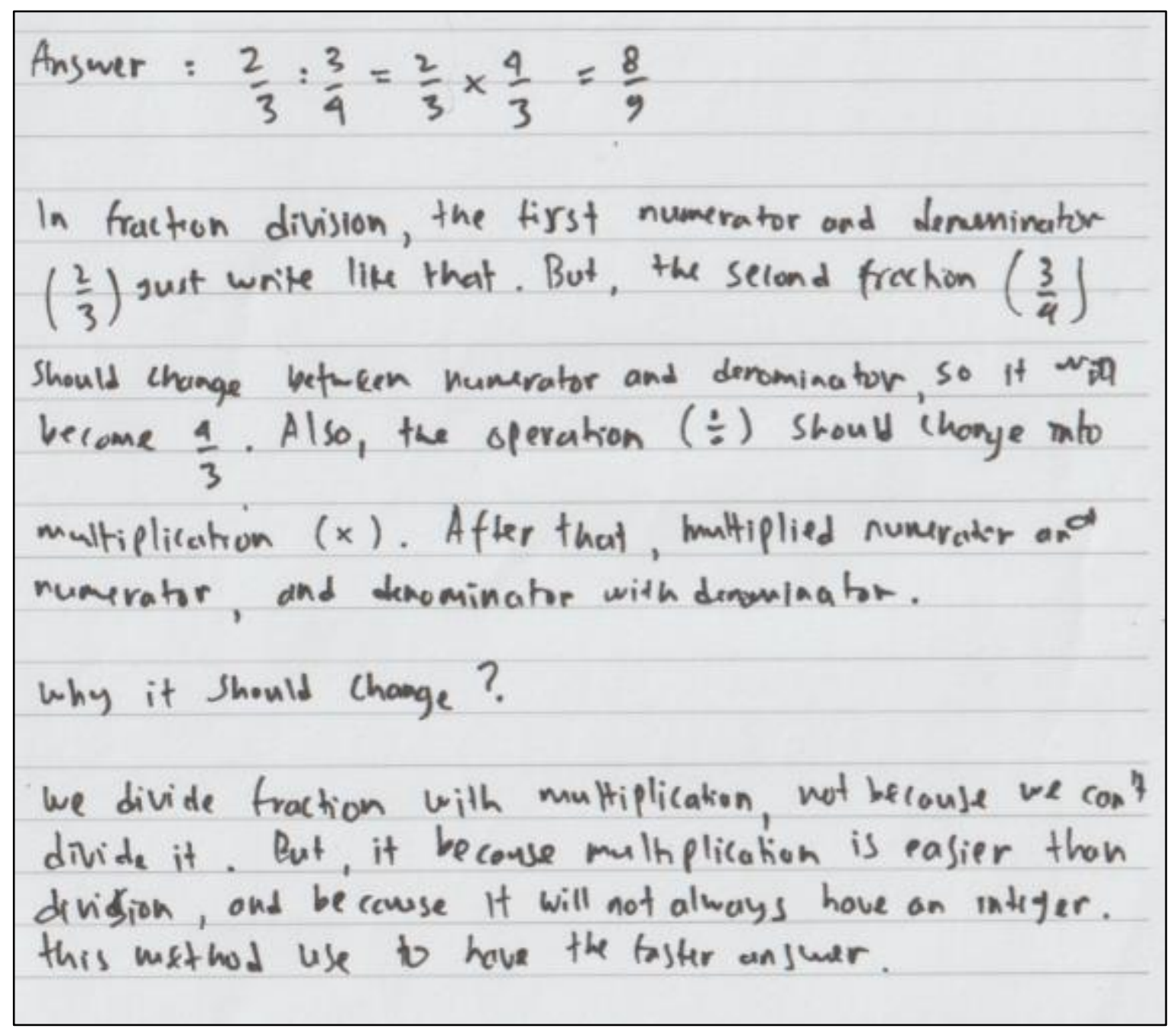

Figure 7. The prospective teacher answer that represents "Keep-Change-Flip" category

After we interviewed one of them to know the reason on their answer (see Figure 7), they still give the reason like the test answer. We ask him what the meaning of using the keep-change-flip algorithm is easier than solve the problem directly. From his answer we know that solve the fraction division problem directly is with repeated substraction and it can't because the first fraction is smaller than the second fraction. Moreover, he just knows about keep-change-flip algorithm to solve the fraction division problem. He doesn't know the other way to solve the fraction division problems. From this interview, we conclude that he understands about fraction division, but he doesn't know why keep-change-flip algorithm can be used to solve the fraction division problems. Also, he just knows that division is a repeated substraction and doesn't know that fraction division can be done with other way.

He said to teach students about fraction division is just directly give the keep-changeflip algorithm. He doesn't understand the meaning of fraction division and the reason why keep-change-algorithm work with fraction division. That's why he prefer just to tell students how to use keep-change-algorithm without telling them either the meaning of fraction division or the reason why keep-change-flip algorithm work.

We turn to prospective teachers that categorized in Not Complete Explanation. There are a quarter of all the prospective teachers that answered correctly and have an explanation, but the explanation is not completed yet. The prospective teachers can answer correctly, but 
there is a missing explanation that should be completed more. He explains that it should be reversed so the denominator can be one and can answer why using a keep-change-flip algorithm is valid mathematically. According to our knowledge, we conclude that prospective teacher answers still not completed yet. After analyzing it, we conducted an interview to know deeper about his understanding of fraction division (see Figure 8).

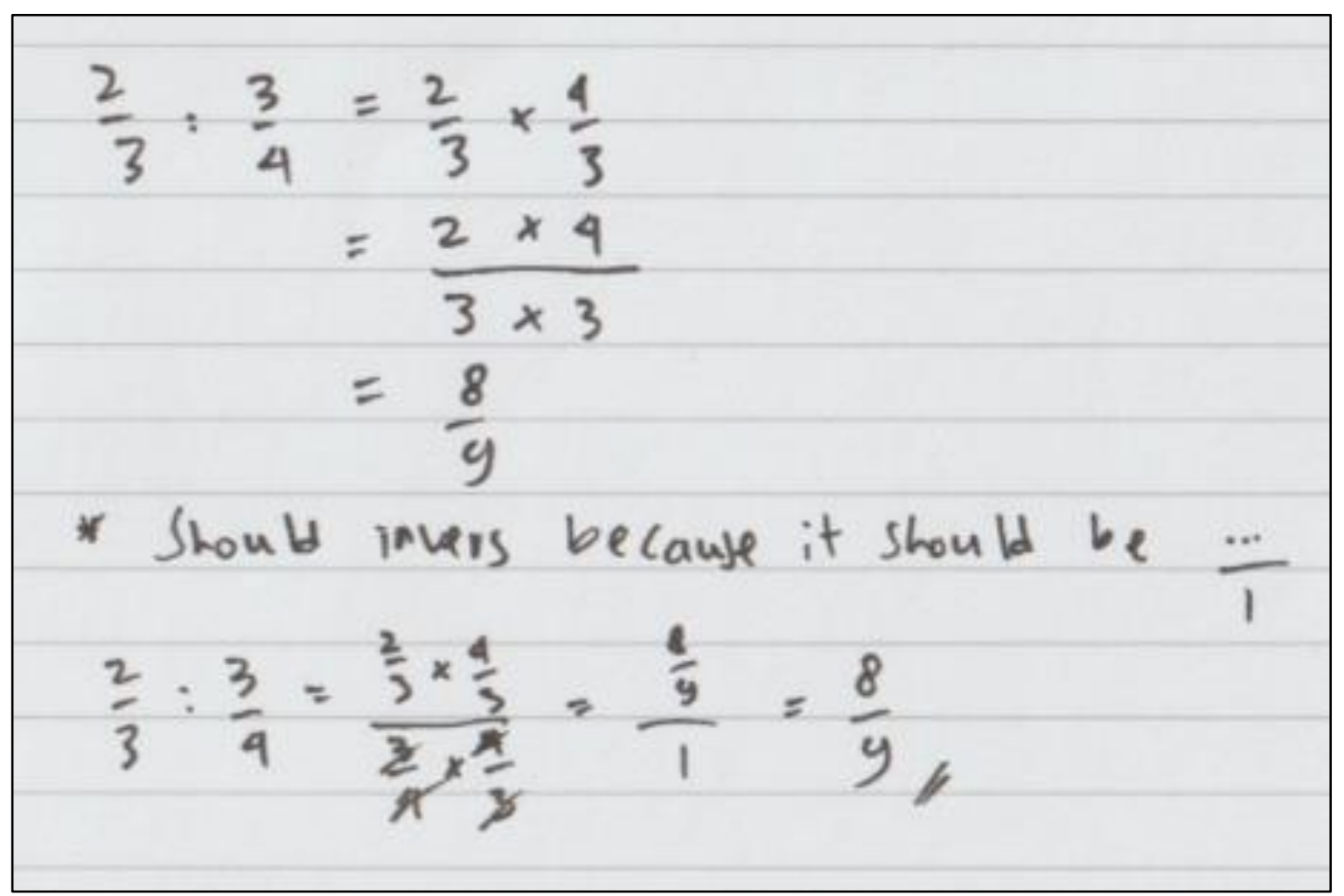

Figure 8. The prospective teacher answer that represents "Not Complete Explanation" category

After been interviewed, he can explain his answer with a good understanding about fraction division. He used keep-change-flip algorithm and he can proof why that algorithm valid mathematically and always used on fraction division problems. Also, he explains that division is a repeated substraction or equal sharing, but they still not understand if the problem is fraction divided by the fraction. He also said that if the lesson of fraction division using rectangle representation is repeated, maybe he will now better the meaning of fraction division.

To teach students about fraction division problems, he will start with the concrete representation that students know. But we know that his answer on the test is not representing a concrete problem, that's why we categorized him to the Not Complete Explanation. Whereas he can explain the meaning of fraction division problems. After that, he explains a way to get the result of fraction division problems by telling them that $\frac{a}{b} \div \frac{c}{d}$ is equal to $\frac{\frac{a}{b}}{\frac{c}{d}}$ and the denominator of that new fraction should be 1, so that's why he multiplied the numerator and denominator of the new fraction with the inverse of the denominator (see Figure 9). 


$$
\frac{a}{b} \div \frac{c}{d}=\frac{\frac{a}{b}}{\frac{c}{d}}=\frac{\frac{a}{b} \times \frac{d}{c}}{\frac{c}{d} \times \frac{d}{c}}=\frac{\frac{a}{b} \times \frac{d}{c}}{1}=\frac{a}{b} \times \frac{d}{c}=\frac{a d}{b c}
$$

Figure 9. The process of solving dividing the fraction by invers method

Different from the others, there are only $15 \%$ prospective teachers participated in this study that answer as expected by us. But at least there are some prospective teachers that can understand about fraction division with the rectangle representation lesson. They can explain how to get the answer without using the keep-change-flip algorithm. They use some rectangle representation but not our rectangle representation that we conducted before. They prefer using vertical and horizontal rectangle representation, it might be easier according to them. They just need to combine the vertical and horizontal rectangle representation and will get how many parts they will get (see Figure 10). We conclude that this way can be used to solve the fraction division problems and we see that they can understand about the fraction division concept.

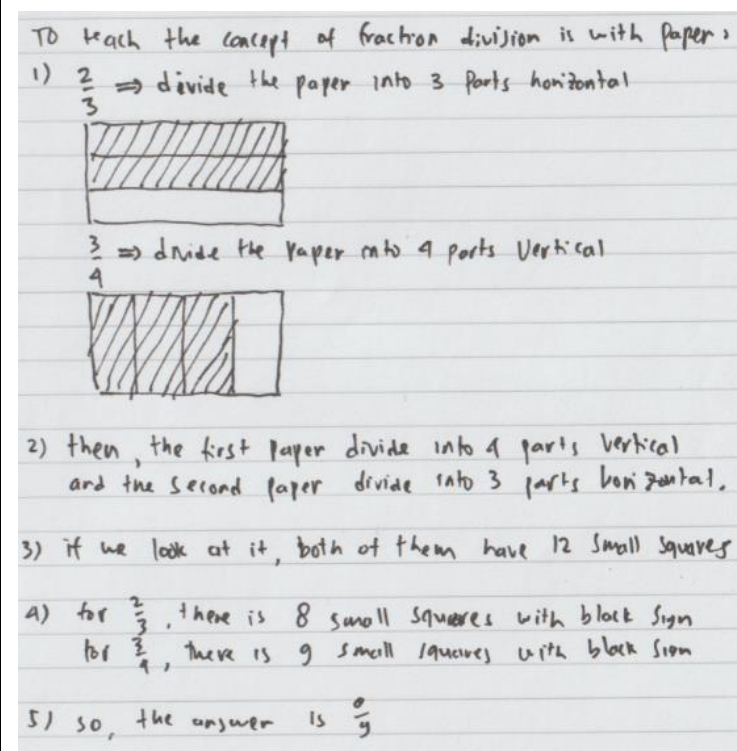

(a)

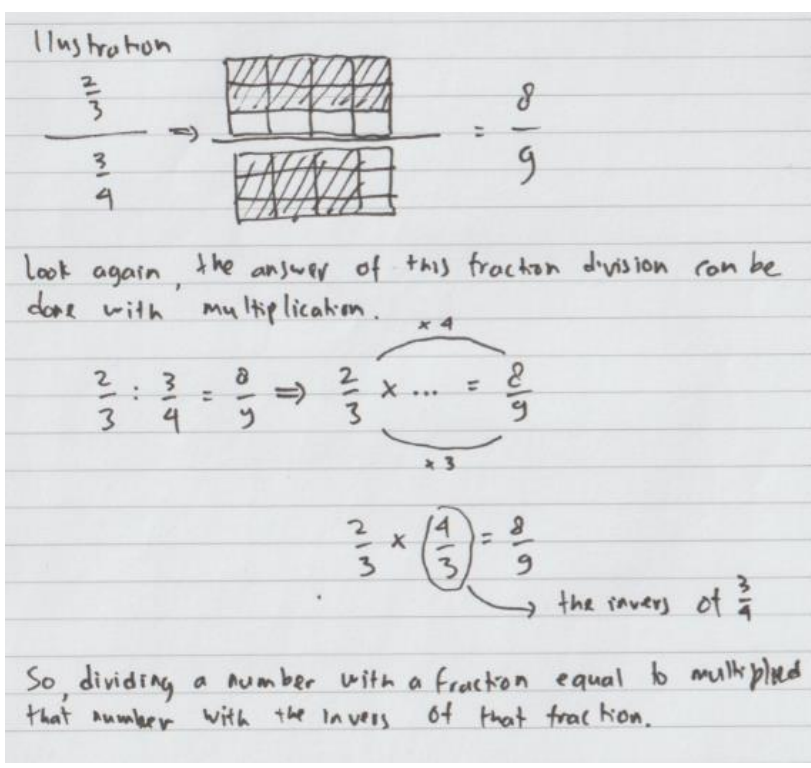

(b)

Figure 10. The prospective teacher answer that represents "Mathematically and Example Explanation" category

After the explanation using rectangle representation, they write about the symbolic statement to solve this fraction division problem. They change the division into multiplication. As we know that if $A \div B=C$ then we can use $B \times C=A$ to solve this fraction division problems. One of prospective teacher can proof why keep-change-flip algorithm used in fraction division problems and valid mathematically. He uses that concept but not all, he assuming what fraction that we can have to make the result of that fraction 
division problem (see Figure 10b). First, he knows that the result is from the rectangle representation (see Figure 10). Then he makes an equation $\frac{2}{3} \times \ldots=\frac{8}{9}$, and try to imagine what is the second fraction if he multiplied it by $\frac{2}{3}$ he will get $\frac{8}{9}$. He can imagine it that the second fraction that make the result is $\frac{8}{9}$ is $\frac{4}{3}$, because $2 \times 4=8$ and $3 \times 3=9$, so he got that $\frac{8}{9}$. After analyzing this answer, we conducted an interview to one of the prospective teachers to know deeper about their answer.

After interviewed, he explains that the meaning of fraction division is when we equal share then count how many dividers that gets from the divided one. Beside that, to proof the keep-change-flip algorithm he uses the concept $A \div B=C$ equivalent to $B \times C=A$ (see Figure 10b). So, he can conclude that keep-change-flip algorithm valid mathematically and can be used to solve fraction division problems.

We asked him to explain how he will teach this fraction division problems to the students. He answers that he will tell the students step by step, from meaning of fraction until the operation, especially fraction division with different denominator. He will use some media to make easier for students to understand. For instance, he will use rectangle representation as he learned before from this class and will developed that media in order to make easier to understand. He tells us that the explanation of our rectangle representation a little bit difficult to understand, he should repeat again and again until he gets the whole meaning of fraction division through that rectangle representation media.

These are the answer that represents for each category that we've been determined before. So, we can assume that some of prospective teachers can understand about fraction division problems using rectangle representation that we used before we conducted the test. And based on the interview, that the answer is diverse and many things that can influence their understanding about fraction division.

\subsection{Discussion}

Based on the results, we can know that many prospective teachers do not understand fraction division. Even we used rectangle representation before the test was conducted. Prospective teachers use the keep-change-flip algorithm to solve the fraction division problems either without knowing whether that algorithm valid mathematically or understanding fraction division problems. They know if they are faced with fraction division problems, they use the keep-change-flip algorithm to solve the problems. It is not essential we understand the concept of fraction division or not. This finding is similar to many previous studies that still many prospective teachers and students that are using a keepchange-flip algorithm without understanding either fraction division concept or proofing keep-change-flip algorithm (Apsari et al., 2020; Bentley \& Bossé, 2018; Purnomo et al., 2019; Sahin et al., 2020; Whitehead \& Walkowiak, 2017).

Most of the prospective teachers still just talk directly about keep-change-flip algorithm without making students understand either about the meaning of fraction division or the reason why keep-change-flip algorithm work with fraction division. This finding is in line with some of recent study that has been done (Apsari et al., 2020; Purnomo et al., 2019). But there are some prospective teachers that will explain the fraction division problems step by step. From representing the problems with a real-life condition, until the students get the abstract concept of fraction division problems. This finding is in line with recent study that teachers will teach students from the concrete one until the abstract (Klemer et al., 2019).

We assume that they still not understand the fraction division concept and keepchange-flip algorithm valid mathematically is because the rectangle representation media 
still not perfect and need to be developed until the audience will understand either about fraction division concept or keep-change-flip algorithm valid mathematically. Different with the domino card media that can make students understand about fraction division (Retnowati et al., 2018).

\section{CONCLUSION}

Based on the results and discussion, there are still many prospective teachers who have not understood the problem of dividing fractions even though they have attended rectangular representation lessons. However, some know either the meaning of fraction division problems or why the keep-change algorithm works with fractional division problems.

The problem of dividing fractions is a problem that is difficult to understand, even for teachers who have taught for a long time. The results showed that most of the prospective teachers still could not imagine how fractions would work. Based on the experiences of researchers since elementary school, we used to solve the problem of dividing fractions with the keep-change-flip algorithm, and it was introduced directly without explaining the concept of fraction division by the teacher. So can cause most prospective teachers not to understand the concept of dividing fractions as a whole.

Most of the prospective teachers informed that they would teach students about the fraction division problem directly using the keep-change algorithm, as this is the easiest way to solve the fraction division problem. However, some prospective teachers will still teach their students in stages, starting from concrete questions to abstract questions about dividing fractions. Therefore, the rectangular media representations still need to be developed, both media and their delivery from the teacher. The next researcher can use this rectangular representation as a reference to make a better media rectangular representation.

\section{REFERENCES}

Adu-Gyamfi, K., Schwartz, C. S., Sinicrope, R., \& Bossé, M. J. (2019). Making sense of fraction division: domain and representation knowledge of preservice elementary teachers on a fraction division task. Mathematics Education Research Journal, 31(4), 507-528. https://doi.org/10.1007/s13394-019-00265-2

Alenazi, A. (2016). Examining middle school pre-service teachers' knowledge of fraction division interpretations. International Journal of Mathematical Education in Science and Technology, 47(5), 696-716. https://doi.org/10.1080/0020739X.2015.1083127

Apsari, R. A., Sariyasa, S., Indrawan, G., \& Maulyda, M. A. (2020). Why should you reverse the order when dividing a fraction? A study of pre-service mathematics teachers' pedagogical content knowledge in fractional concept. Journal of Physics: Conference Series, 1503(1), 012019. https://doi.org/10.1088/17426596/1503/1/012019

Bentley, B., \& Bossé, M. J. (2018). College students' understanding of fraction operations. International Electronic Journal of Mathematics Education, 13(3), 233247. https://doi.org/10.12973/iejme/3881

Ervin, H. K. (2017). Fraction multiplication and division models: A practitioner reference paper. International Journal of Research in Education and Science, 3(1), 258-279. 
Fitri, N. L., \& Prahmana, R. C. I. (2019). Misconception in fraction for seventh-grade students. Journal of Physics: Conference Series, 1188(1), 012031. https://doi.org/10.1088/1742-6596/1188/1/012031

Haji, S. (2013). Pendekatan Iceberg dalam pembelajaran pembagian pecahan di sekolah dasar. Infinity Journal, 2(1), 75-84.

Klemer, A., Rapoport, S., \& Lev-Zamir, H. (2019). The missing link in teachers' knowledge about common fractions division. International Journal of mathematical education in science and technology, 50(8), 1256-1272. https://doi.org/10.1080/0020739X.2018.1522677

Konak, A., Clark, T. K., \& Nasereddin, M. (2014). Using Kolb's Experiential Learning Cycle to improve student learning in virtual computer laboratories. Computers \& Education, 72, 11-22. https://doi.org/10.1016/j.compedu.2013.10.013

Purnomo, Y. W., Widowati, C., \& Ulfah, S. (2019). Incomprehension of the Indonesian elementary school students on fraction division problem. Infinity Journal, 8(1), 5774. https://doi.org/10.22460/infinity.v8i1.p57-74

Retnowati, R. P., Kamsiyati, S., \& Matsuri, M. (2018). Improving fraction operation skills of multiplication and division through the application of domino card to student of grade v sdn 02 pulosari academic year 2017/2018. Social, Humanities, and Educational Studies (SHEs): Conference Series, 1(1), 711-717. https://doi.org/10.20961/shes.v1i1.23626

Sahin, N., Gault, R., Tapp, L., \& Dixon, J. K. (2020). Pre-service teachers making sense of fraction division with remainders. International Electronic Journal of Mathematics Education, 15(1), em0552. https://doi.org/10.29333/iejme/5934

Stohlmann, M., Yang, Y., Huang, X., \& Olson, T. (2020). Fourth to sixth grade teachers' invented real world problems and pictorial representations for fraction division. International Electronic Journal of Mathematics Education,15(1), em0557. https://doi.org/10.29333/iejme/5939

Whitehead, A., \& Walkowiak, T. A. (2017). Preservice elementary teachers' understanding of operations for fraction multiplication and division. International Journal for Mathematics Teaching and Learning, 18(3), 293-317.

Widada, W., Herawaty, D., Lusiana, D., Afriani, N. H., Sospolita, N., Jumri, R., \& Trinofita, B. (2020). How are the process of abstraction of the division of fraction numbers by elementary school students?. Journal of Physics: Conference Series, 1657(1), 012040. https://doi.org/10.1088/1742-6596/1657/1/012040

Yeo, S. (2019). Investigating children's informal knowledge and strategies: The case of fraction division. Research in Mathematical Education, 22(4), 283-304. https://doi.org/10.7468/jksmed.2019.22.4.283 